\title{
Seismic damage assessment of mountain tunnel: a case study on the Tawarayama Tunnel due to the 2016 Kumamoto Earthquake
}

\author{
Xuepeng Zhang ${ }^{\mathrm{a}, \mathrm{b}} \quad$ Yujing Jiang*a,b $^{\mathrm{a}}$ Satoshi Sugimoto ${ }^{\mathrm{a}}$
}

a) School of Engineering, Nagasaki University, 1-14 Bunkyo-machi, 8528521 Nagasaki, Japan

b) State Key Laboratory of Mining Disaster Prevention and Control Co-founded by Shandong Province and the Ministry of Science and Technology, Shandong University of Science and Technology, Qingdao 266590, China

Corresponding author: Yujing Jiang

Corresponding Address:

School of Engineering, Nagasaki University,1-14 Bunkyo-machi, 8528521 Nagasaki, Japan.

E-mail: jiang@nagasaki-u.ac.jp

Tel: +81 958192612 
1 Abstract

2 The Kumamoto Earthquakes with magnitude of 7.3(Mj) on April 16 and 6.5(Mj) on April 14,

32016 have triggered numerous damages to the Tawarayama Tunnel in Kumamoto Prefecture,

4 Japan. Distribution and characteristics of these seismic damages were investigated and

5 summarized to assess potential influencing factors. Seismic damages are categorized into five

6 patterns as follows: lining cracks, spalling and collapse of concrete lining, construction joint

7 damage, pavement damage and groundwater leakage. Lining cracks can be further classified

8 into ring crack, longitudinal crack, transverse crack and inclined crack. Site investigation

9 showed the primary seismic damage was lining crack, especially ring crack. In special, an interesting phenomenon was observed that ring cracks occurred with an estimated average spacing of $10.0 \mathrm{~m}$ in $23.4 \%$ spans of the Tawarayama Tunnel. This results from the interaction between seismic wave and special geological conditions that dense Andesite and crushed Andesite around the Tawarayama Tunnel appear in tilt alternately with space between $10 \mathrm{~m}$ and $20 \mathrm{~m}$. Following these analysis, some recommendations were proposed for future tunnel planning.

Keywords: 2016 Kumamoto Earthquake; Tawarayama Tunnel; seismic damage; influencing factor

\section{Introduction}

Tunnel is generally divided into two types: shallow-buried urban tunnel and deep-buried mountain tunnel. It was widely accepted that mountain tunnel was assumed to be seismic resistant due to being situated deep with rock layers(Towhata et al, 2008). Therefore, studies of mountain tunnel damages by earthquakes were limited. Whereas, three strong earthquakes involving the 1995 Kobe Earthquake occurred in Japan, the 1999 Chi-Chi Earthquake in Taiwan and the 2008 Wenchuan Earthquake in Sichuan province of China have given strike on this tradition view. Among them, $12 \%$ of mountain tunnels in the epicentral area in the 
Kobe Earthquake were damaged severely(Yashiro et al, 2007), 26\% of 50 tunnels located with $25 \mathrm{~km}$ of the earthquake fault in the Chi-Chi Earthquake damaged heavily and 22\% moderately damaged(Wang et al, 2001), and 73\% of 18 tunnels located in the Du (Du-jiang-yan)-Wen (Wen-chuan) highway in the Wenchuan Earthquake severely damaged and 22\% damaged moderately(Wang et al, 2009). The damages to mountain tunnels by earthquakes occurred in recent years have attracted much higher attention on seismic effect of earthquake on mountain tunnels.

Thus, conspicuous efforts of collection and classification on seismic damages to mountain tunnels due to earthquakes have been taken by many researchers, such as Dowding and Rozan(1978), Asakura (1996), Wang et al(2009), Li et al(2012), and Chen et al(2012). Dowding and Rozan (1978) suggested three forms of the seismic damages: damage by earthquake-induced ground failure, damage from fault displacement and damage from ground shaking or vibration. After the Taiwan Chi-Chi Earthquake in 1999, Wang et al(2001) classified the damages into six types: sheared off lining, slope failure induced tunnel collapse, lining cracks, pavement or bottom cracks, wall deformation and cracks that develop near opening. Li et al(2012) analyzed characteristics of tunnel failures following the Wenchuan Earthquake in 2008 and categorized them into six types: avalanches and sliding towards the tunnel portal, cracking of the tunnel portals, collapse of the liner and surrounding rock, failure and dislocation of the lining, uplift and cracking of the tunnel invert, deformation and cracking of the preliminary bracing. Chen et al(2012) based on previous studies to summarize seven common damage characteristics according to manner of the structural damages: lining cracks, shear failure of lining, collapse caused by slope failure, portal cracking, leakage, wall deformation, and invert damage. In addition, database for seismic damages to tunnels due to earthquakes were developed to analyze main factors affecting stability of underground structures (Sharma and Judd, 1991) with case histories and remediation methods (Lanzano et al, 2008). Much more detailed site investigation and analysis on tunnel seismic damage have 
been carried out by other researchers for the 1995 Great Hanshin Earthquake(Asakura et al 1998), the 2004 Mid Niigata Prefecture Earthquake(Shimizu et al, 2005, 2007; Yashiro et al, 2007; Konagai et al, 2008; Jiang et al, 2010), the 2007 Niigata Prefecture Chuetsu Offshore Earthquake(Saito et al, 2007), the 2008 Wenchuan Earthquake(Wang et al, 2009; Shen et al, 2014; Yu et al, 2013, 2016a, 2016b).

In this study, distribution and characteristics of seismic damages to the Tawarayama Tunnel were investigated and summarized to assess potential influencing factors. Aimed at the axially regularly distributed ring cracks, preliminary discussion on its cause involving seismic wave and geological conditions were conducted. And some recommendations were proposed for future tunnel planning based on these analysis.

\section{Kumamoto Earthquake's damages to the Tawarayama Tunnel}

\subsection{Project of the Tawarayama Tunnel}

The Tawarayama Tunnel is located at a distance of about $22.4 \mathrm{~km}$ from the epicenter of the mainshock(Mj7.3) as shown in Fig.1. The total length of the tunnel is $2057 \mathrm{~m}$ with horseshoe cross section. Fig. 2 shows the typical cross section of the tunnel. The typical cross section has a total width of $10.20 \mathrm{~m}$ and a maximum height of $7.97 \mathrm{~m}$. Fig. 3 presents the geological profile of the tunnel. Its maximum overburden is about $300 \mathrm{~m}$. The Tawarayama Tunnel runs through three different formations: the Quaternary Holocene, the Quaternary Pleistocene and the Tertiary Pliocene. The portal area is excavated in Talus and Early Stage Talus deposites composed of welded tuff, gravel, silt and clay. The tunnel is excavated in the Andesite lava. Based on the Japanese Technical Standard for Structure Design of Road Tunnel(JARA, 2003), rock mass along the tunnel(Fig.3) is organized into four classes, involving $C_{I I}, D_{I}, D_{I I}$ and $\mathrm{D}_{\mathrm{III}}$.

Excavation method of the Tawarayama Tunnel is New Austrian tunnelling method(NATM). NATM is assumed to be much better than the traditional method based on the conditions after 
earthquakes. This is because interaction between surrounding rock and tunnel using NATM performs better than that using traditonal method(Chen et al, 2012) . Support systems of the tunnel consist of primary support, waterproof layer, and secondary support. The primary support include shotcrete $\left(0.10 \mathrm{~m}, 0.15 \mathrm{~m}, 0.20 \mathrm{~m}\right.$ and $0.25 \mathrm{~m}$ for rock calss $\mathrm{C}_{\mathrm{II}}, \mathrm{D}_{\mathrm{I}}, \mathrm{D}_{\mathrm{II}}$ and $\mathrm{D}_{\text {III }}$, respectively) and rockbolt. For rock class $\mathrm{D}_{\mathrm{I}}, \mathrm{D}_{\text {II }}$ and $\mathrm{D}_{\text {III }}$, the rockbolts are distributed on a grid of $1.2 \mathrm{~m} \times 1.0 \mathrm{~m}$ and have a length of $4.0 \mathrm{~m}$. For rock class $\mathrm{C}_{\mathrm{II}}$, the rockbolts are distributed on a grid of $1.5 \mathrm{~m} \times 1.2 \mathrm{~m}$ and have a length of $3.0 \mathrm{~m}$. Besides, for rock class $\mathrm{D}_{\mathrm{III}}$, forepoling is conducted, especially at the portals. The rockbolts are spaced on a grid of 0.60 $\mathrm{m} \times 1.0 \mathrm{~m}$ with length of $3.0 \mathrm{~m}$. The secondary lining is reinforced concrete with a thickness of $0.30 \mathrm{~m}$.

\subsection{Overview of the Kumamoto Earthquakes and seismic damages to the Tawarayama Tunnel}

The 2016 Kumamoto Earthquakes were a series of earthquakes, including a foreshock (the epicenter located at 32.742N,130.808E) with a magnitude 6.5(Mj) at 21:26 JST on April 14, 2016, at a depth of about $11 \mathrm{~km}$, and a magnitude 7.3(Mj) mainshock (the epicenter located at 32.753N,130.762E) which struck at 01:25 JST on April 16, 2016 at a depth of about $12 \mathrm{~km}$ (Asian Disaster Reduction Center) beneath Kumamoto City of Kumamoto Prefecture in Kyushu Region, Japan. Fig. 4 illustrates distribution of peak acceleration of both the foreshock and mainshock according to the National Research Institute for Earth Science and Disaster Prevention of Japan. The acceleration waves measured at the Nakamatsu observation site(Fig.1) during the mainshock on April 16, 2016 are depicted in Fig.5. The Nakamatsu observation site is located at the northeast of epicenter with a distance of $32.3 \mathrm{~km}$. Acceleration of the mainshock from time of 15 second to 30 second at Nakamatsu observation site is shown in Fig.5b. The seismic records consist of three components along the NS (North-South), EW (East-West) and UD (Up-Down) directions. The NS and EW waves represent horizontal motions of ground surface, and the UD wave represents vertical 
motion of ground. Maximum values of the NS, EW and UD accelerations are 794.3 gal $\left(\mathrm{cm} / \mathrm{s}^{2}\right), 606.6$ gal $\left(\mathrm{cm} / \mathrm{s}^{2}\right)$ and 652.9 gal $\left(\mathrm{cm} / \mathrm{s}^{2}\right)$, respectively. Table 1 lists measured maximum ground acceleration at various observation site induced by the mainshock. Due to the fact that the EW and NS components have larger seismic amplitude, damages to rock foundations and buildings caused by horizontal motion are much more severe than those caused by vertical motion. Besides, for the mainshock, at the Kumamoto GEONET station (32.8421N, 130.7648E), $0.75 \mathrm{~m}$ horizontal deformation in the ENE direction and $0.20 \mathrm{~m}$ downward deformation were recorded, at the Choyo GEONET station (32.8707N, 130.9962E), $0.97 \mathrm{~m}$ horizontal deformation in the SW direction and $0.23 \mathrm{~m}$ upward deformation were recorded(Goda et al, 2016). Field investigation of Lin et al(2016) also showed that the horizontal displacement caused by the seismic along fault accounted for a larger proportion.

Numerous patterns of seismic damages to the Tawarayama Tunnel were observed as follows: lining cracks, construction joint damage, groundwater leakage, spalling and collapse of concrete lining and pavement damage. Detailed surveys were performed using lining crack mapping, photo recording and measuring major-crack characteristics(including width, length and depth). Fig. 6 presents distribution of seismic damages to the Tawarayama Tunnel by the 2016 Kumamoto Earthquakes.

Among the seismic damages, lining cracks dominated with estimated number proportion of $66.5 \%$, consisting of ring crack(23.9\%), transverse crack(9.6\%), longitudinal $\operatorname{crack}(13.0 \%)$ and inclined crack(20.0\%). Statistic and proportion of seismic damages to the Tawarayama Tunnel by the 2016 Kumamoto Earthquake are shown in Fig.7. The lining cracks, especially ring cracks, mainly occurred in the spans of S004 S005, S028 S053, S067 S071, S094 S097, S119 S126, S146 S168, S184 S190(S is short for Span), with length of $783.2 \mathrm{~m}(38.1 \%$ of the Tawarayama Tunnel total length $2057 \mathrm{~m})$. Fig.8 shows sketch of the seismic damages in these spans of the Tawarayama Tunnel. 
At the portal(S001) near the Nishihara Village, pavement in the spans from S001 to S030 was observed to uplift and crack continuously. And most of pavement uplift developed on the left side along maintaining roadway. Besides, in the spans from S158 to S168, pavement suffered cracking with maximum opening of $10 \mathrm{~cm}$ between S167 and S168. Construction joint was damaged severely at the portal(S001) near the Nishihara village with maximum opening of $10 \mathrm{~cm}$ between S001 and S002. And construction joint opening decreased with the tunnel extending to the Minami Aso Village side. From the span of S098, severe construction joint damage was seldom observed. Groundwater leakage mainly occurred along with lining cracks near the Minami Aso Village.

\section{Classification and mechanism analysis on seismic damages}

Various patterns of seismic damages to the Tawarayama Tunnel by the 2016 Kumamoto Earthquakes were observed. Some of the major patterns with significant characteristics were illustrated and their potential influencing factors were also discussed.

\section{1 lining cracks}

Ring cracks with maximum dislocation of $8.0 \mathrm{~mm}$ were the most frequently observed in the Tawarayama Tunnel. Spans from S119 to S126 are representative examples(Fig. 9a). The ring cracks can be further classified into two types: transverse ring cracks and inclined ring cracks. Sketch and mapping results of these two types of ring cracks are shown in Fig.9b. Damage of this pattern was also found in the Zipingpu Tunnel, the Longdongzi Tunnel and the Longxi Tunnel built on the Chendu-Wenchuan Line in China following the 2008 Wenchuan Earthquake(Li et al, 2012).

Pattern of longitudinal cracks of concrete lining was another severe one. They were much less than ring cracks. Most longitudinal cracks occurred at the portal(S001) near the Nishihara Village. Fig.10 illustrates longitudinal cracks occurred in the Tawarayama Tunnel. This damage pattern can be further classified into three types: singular crack at the vault of the 
crown, symmetrical crack and non-symmetric crack(Wang et al, 2001). In the Tawarayama Tunnel, most of the longitudinal cracks were the former one(Fig.10a). And length of some longitudinal cracks exceeded dimension of the lining span(about $10 \mathrm{~m}$ )(Fig.10b). In addition, a pair of symmetrical cracks were observed at span of S007, and a few non-symmetric cracks occurred at the sidewall at spans of S140, S184 and S188 near the Minami Aso Village. In the Chi-Chi Earthquake, the No. 1 San-I Railway Tunnel, the New Chi-Chi Tunnel on Highway No. 16 and the headrace tunnel of New Tienlun power station were the most representative examples of this type of damage( Wang et al, 2001). And longitudinal cracks also occurred in the Namutani Tunnel in the Great Kanto Earthquake in Japan(Gong, 2007).

Transverse cracks that developed perpendicular to direction of the tunnel axis and inclined cracks with inclination of $40-70^{\circ}$ to direction of the tunnel axis were observed to mainly develop at the hance and sidewall, dominated by shearing type and tension-shearing type. Some ring cracks developed from propagation and interaction of transverse and inclined cracks. Both transverse and inclined cracks are illustrated in Fig.11.

Axial deformation mode and mechanism of mountain tunnels under seismic wave are depicted in Fig.12. When axial stress(compression or tension) along the tunnel extension direction exceeds the corresponding (compression or tensile)strength of the lining concrete, cracks especially ring cracks and transverse cracks may initiate and develop. Relative movement between different span of the tunnle along the tunnel axis contributes to these damages. Influencing factors for the relative movement involve seismic wave, geological conditions, lining conditions, and so forth.

The epical center located in the southwest direction and seismic wave obliquely propagated crossing the tunnel axis. In general, seismic wave parallel to or obliquely crossing the tunnel axis result in kinds of axial deformations, such as axial tension, compression and bending deformation. Chen(2011) also pointed out that the axially propagating P wave could cause tension-compression stress, and once the stress exceeds strength of lining concrete, ring 
cracks may occur. Response Displacement Method was also taken to illustrate that ring crack occurs on the lining when the actual strain in the lining concrete exceeds its ultimate strain (Yu et al, 2013). Besides, S wave perpendicular to or in $45^{\circ}$ incident angle to the tunnel axis was verified to have a significant effect on initiation and propagation of longitudinal cracks by finite element method(FEM)(Chen et al, 2006). Besides, the Futagawa Fault Zone, whose general strike is NE-SW, obliquely crosses axis of the Tawarayama Tunnel with general strike of W-E(Fig.1). Dislocation of the Futagawa Fault Zone with estimated maximum of $2.2 \mathrm{~m}$ (in Mashiki) by earthquake could accelerate the tunnel axial deformation.

A great difference between above-structure and underground structure is that the latter is in combination with a surrounding medium, namely soil or rock(Chen et al, 2012). So, geological conditions significantly affect seismic response of mountain tunnels. Existing of fault zone and imperfection of contact between tunnel lining and surrounding rock could aggravate the axial deformation. Near the portal(S012 S013), unsymmetrical loading due to slope above the tunnel moved span of S012 towards south direction(lower side of the portal slope) in $10 \mathrm{~cm}$. Cross section here underwent compression and bending deformation, resulting in longitudinal cracks along with concrete lining spalling. Hence, for future tunnel planning, it is advised to avoid placing tunnel too close to slope faces if possible. If not, it is important to take into account the slope stability evaluation and integrated design about the non-buried tunnel section and tunnel portal structure. For lining conditions, three aspects involving presence or absence of lining, lining material and lining stiffness to some extent influence development of lining cracks(Wang et al, 2001; Power et al,1998; Li et al, 2006).

\subsection{Spalling and collapse of concrete lining}

Fig.13 shows spalling and collapse of concrete lining in the Tawarayama Tunnel. Concrete lining spalling at the sidewall often developed along with lining cracks, especially inclined cracks(Fig.13a). Besides, large area of secondary concrete lining was observed to collapse, 

especially at spans of S166 and S167(Figs.13b and 13c). In the 1995 Chi-Chi earthquake(Wang et al, 2001) and the 2008 Wen-Chuan Earthquake(Li et al, 2012; Yu et al, 2016), lining spalling and collapse were representative seismic damages in numerous mountain tunnels, such as the No. 1 San-I railway tunnel, the Loingxi Tunnel, et al. For lining spalling and collapse, seismic force is the initiation factor. Deformation mechanism of mountain tunnel cross section under seismic wave is depicted in Fig.14. When seismic wave propagates normal or nearly normal to tunnel axis, shape of tunnel cross section would be distorted, resulting in development of ovaling deformation or compression deformation of tunnel cross section. Moment and axial force then varies along with these deformation. Once local stress or moment surpasses corresponding strength, lining spalling may occur with interaction of squeezing, and even highly excessive compression may cause collapse of the concrete lining. Because seismic wave of the Kumamoto Earthquake propagated obliquely crossing the tunnel axis, component of seismic wave normal to the tunnel axis could lead to these seismic response. Furthermore, high frequency motion is assumed to be a reason for the local spalling of concrete lining along weak section(Wang et al, 2009).

Geological investigation indicated that loosen zone of surrounding rock existed around the Tawarayama Tunnel along the east slope of the Tawarayama Mountain. And forensic investigation showed that there were gravels in the waterproof at spans of S166 and S167. The loosen surrounding rock and cavity existing behind the lining influenced imperfection of contact between tunnel lining and surrounding rock, leading to spalling of concrete lining, even collapse of tunnel structure. Spans of S166 and S167 are also at the tunnel turning corner(Fig.3), which may result in unexpected seismic response to make these spans vulnerable. Therefore, tunnel sections with turning, sudden changes in form, intersections of two tunnels and emergency parking places, et al., require more attention during the design and construction of tunnel. A large fault was found to exist over the spans of S166 and S167 through in-situ investigation, in consistent with the secondary concrete lining collapse. 
230 Tunnels that go through fault or shear areas or into a large plastic area are more likely to show collapse. Therefore, for future tunnel planning, efforts should be made to avoid running cross active fault zones or weak surrounding rock where possible. When crossing faults, reinforced countermeasures should be taken into consideration for the concrete lining.

\subsection{Pavement damage}

Uplift and cracking of pavement were frequently observed at the portal(S001) of the Tawarayama Tunnel near the Nishihara village. Fig.15 shows pavement damage in the Tawarayama Tunnel. Damage of this pattern can be further classified into three types: transverse fracture and dislocation (maximum opening, $10 \mathrm{~cm}$ ) (Fig.15a), maintaining roadway uplift(maximum, $55 \mathrm{~cm}$ ) (Fig.15b), invert uplift(maximum, $20 \mathrm{~cm}$ ).

The fact that pavement damage observed in the Tawarayama Tunnel ran continuously over a long distance in the longitudinal direction at the portal(S001) near the Nishihara village indicates that the epicentral distance $(22.4 \mathrm{~km})$ has a significant effect. This coincides with the statement of Shen(2014) that portals near the epicenter(less than $30 \mathrm{~km}$ ) often suffer extremely severe damage. Movement $(10 \mathrm{~cm})$ of span S012 towards south direction due to unsymmetrical loading near the portal provided an good explanation for the phenomenon that maintaining roadway uplifted along the left side of pavement, especially at the span of S012 with the maximum uplift of $55 \mathrm{~cm}$. Besides, the portal of the Tawarayama Tunnel is excavated in a relatively loose quaternary formation. Ground motion may be amplified at the portal section, which can result in the larger seismic inertia force. And dense Andesite and crushed Andesite appear alternately along the Tawarayama Tunnel extending direction, which may lead to transverse fracture and dislocation at the interface between soft and hard rock. Moreover, due to abrupt changes of tunnel cross section or turning of tunnel, stress variation of tunnel is also regarded as one of main causes for tunnel pavement damage. In the present study, spans ranging from S150 to S200 at the turn of the Tawarayama Tunnel were 
representative examples(Fig.15a).

\subsection{Groundwater leakage}

Seventeen groundwater leakages were counted totally in the Tawarayama Tunnel. The patterns of groundwater leakage can be further classified into two types: leakage in construction joint(Fig.16a) and leakage in concrete lining(Fig.16b). The latter one often occurred in the concrete lining with cracks or concrete spalling. The leakages in the spans from S166 to S167 of the Tawarayama Tunnel were representative illustrations(Fig.16b). Large areas of leakage were found in No.2 and No.3 Lines of Guanyin Tunnel and the Old Guguan Tunnel after the 1999 Chi-Chi Earthquake(Chen et al, 2012). And three types of groundwater inrush including soakage, dropping and pouring in construction joint were observed in 6 tunnels after the 2008 Wen-chuan Earthquake(Wang et al, 2009). Leakage may occurs where groundwater is abundant. And the seismic damages to concrete lining and pavement due to earthquakes discussed above are preconditions for damage of this pattern.

\section{Discussion}

A special and interesting phenomenon was observed during site investigation for the Tawarayama Tunnel that 55 ring cracks distributed with a regular spacing $\Delta$ in $23.4 \%$ spans of the Tawarayama Tunnel. They mainly concentrated in S030 S053, S095 S097, S119 S126, S146 S153, S157 S165, S184 190(Fig.8). Fig.17 provides a further sketch illustration of ring crack distribution and corresponding estimated spacing. Fig. 18 illustrates estimated spacing of the regularly distributed ring cracks in the Tawarayama Tunnel. The spacing was estimated to be about $10.0 \mathrm{~m}$.

The general seismic propagation direction during the strong earthquake is oblique to the tunnel axis, as discussed in Part 3.1. Seismic wave parallel or obliquely crossing the tunnel axis causes longitudinal motion of the tunnel involving axial tension, compression and bending deformation. So once corresponding(compression or tensile) strength of the concrete 
is reached, ring crack is expected. This coincides with the ring cracks observed in the Tawarayama Tunnel. Meanwhile, longitudinal motion is aggravated by the geological conditions to form this special phenomenon. According to the in-situ geological investigation, dense Andesite and crushed Andesite along the Tawarayama Tunnel appear in tilt alternately with space between $10 \mathrm{~m}$ and $20 \mathrm{~m}$ (Fig.3). Because of different wave velocities, wave dispersion and ground resistance in soft and hard rock, soft and hard grounds behave differently during earthquakes. So seismic damages to tunnel structure normally occur in the soft ground or at the intersection of different rock grades by ground relative displacement or ground squeeze where soft and hard grounds meet(Yu et al, 2016).

This indicates that longitudinal motion of mountain tunnels under earthquake should be paid much more attention in the aseismic design and construction procedure. Mitigation countermeasures for the longitudinal seismic response can be taken into consideration for further mountain tunnel construction and remediation process, such as ring shock absorption structure. It can absorb longitudinal seismic energy while maintain the intact horseshoe shape of tunnel cross section with full ability to undertake vertical pressure from the surrounding rock and other external force. Further detailed studies on theoretical and engineering mechanism of the axial regularly distributed ring damages in mountain tunnels by earthquake and corresponding mitigation countermeasures such as ring shock absorption structure should be investigated.

\section{Conclusions}

(1)Seismic damages to the Tawarayama Tunnel due to the 2016 Kumamoto Earthquake were investigated and summarized as follows: lining cracks, lining concrete spalling and collapse, pavement damage, groundwater leakage and construction joint damage. Ring cracks were the most frequently observed, accounting for $23.9 \%$ of the total damages in number. Influencing factors for each pattern of seismic damages involve characteristics of seismic wave, 
conditions of concrete lining and geological conditions including quality of surrounding rock mass, fault zone, etc. A special and interesting phenomenon was observed that 55 ring cracks distributed with an estimated average spacing $10.0 \mathrm{~m}$ in $23.4 \%$ spans of the Tawarayama Tunnel. This results from interaction between seismic wave and special geological conditions that dense Andesite and crushed Andesite around the Tawarayama Tunnel appear in tilt alternately with space between $10 \mathrm{~m}$ and $20 \mathrm{~m}$.

(2)Following the analysis on the seismic damages and corresponding influencing factors to the Tawarayama Tunnel under earthquake, some recommendations for future aseismic tunnel planning are given as follows:

- Tunnel should be placed far away from slope faces if possible. If not, it is important to simultaneously take into account the slope stability evaluation and integrated design about the non-buried tunnel section and tunnel portal structure.

- It is advised to avoid tunnel running cross active fault zones or weak surrounding rock if possible. When crossing faults, reinforced countermeasures should be taken into consideration for the concrete lining.

- Longitudinal motion of mountain tunnels under earthquake should be paid much more attention in the aseismic design and construction procedure. Mitigation countermeasures for the longitudinal seismic response can be taken into consideration for further mountain tunnel construction and remediation process, such as ring shock absorption structure.

(3)For further understanding on theoretical and engineering seismic response and mechanism of mountain tunnels under earthquake, efforts should be taken on these aspects as follows:

- longitudinal response of mountain tunnel under earthquake in three dimension;

- effect of ground surface motion under seismic wave on performance of mountain tunnel;

- corresponding mitigation countermeasures with consideration of longitudinal shock absorption. 
330 Acknowledgement

331 This work was funded by National Natural Science Foundation of China (No. 51379117) and 332 China Scholarship Council (CSC No. 201508370077). The authors also gratefully 333 acknowledge support of the Kumamoto River and National Highway Office, Kyushu 334 Regional Development Bureau, Ministry of Land, Infrastructure, Transport and Tourism in 335 the site investigation of this study. 


\section{References}

Asakura T., Sato Y., 1996. Damage to Mountain Tunnels in Hazard Area. Soils Found. Special Issue, 301-310.

Asakura T., Sato Y., 1998. Mountain tunnels damage in the 1995 Hyogoken-nanbu Earthquake. Q Rep RTRI(Railway Technical Research Institute) 39(1):9-16.

2016 Kumamoto Earthquake Survey Report (Preliminary). Asian Disaster Reduction Center, 2016.

Chen C., Huang T, 2006. Preliminary study on the failure pattern and mechanisms for mountain tunnels//The Fifth Session of Two Sides Across the Taiwan Strait Tunnel and under Structure Work Academic and Technical Seminar. Taipei, 1-8.

Chen C., Wang T., Huang T., 2011. Case study of earthquake-induced damage patterns of rock tunnel and associated reason. Chin. J. Rock Mech. Eng. 30(1), 045-057.(in Chinese)

Chen Z., Shi C., Li T., et al, 2012. Damage characteristics and influence factors of mountain tunnels under strong earthquakes. Nat. hazards 61(2), 387-401.

Dowding C. H., Rozan, A.,1978. Damage to rock tunnels from earthquake shaking. J. the Soil Mech. Foundations Div. 104(2), 175-191.

Goda K., Campbell G., Hulme L., et al, 2016. The 2016 Kumamoto earthquakes: cascading geological hazards and compounding risks. Frontiers in built environment, 2: 19.

Gong Z.H., 2007. Study on the seismic safety evaluation of Huangcaoping Tunnel of National Road No. 318.Dissertation, Chengdu University of Technology. (in Chinese)

Japan Road Association. Technical standard for structure design of road tunnel. 2003. (in Japanese)

Jiang Y.J., Wang C.X., Zhao X.D., 2010. Damage assessment of tunnels caused by the 2004 Mid Niigata Prefecture Earthquake using Hayashi's quantification theory type II. Nat. hazards 53(3), 425-441. 
Lanzano G., Bilotta E., Russo G., 2008.Tunnels under seismic loading: a review of damage case histories and protection method. Presented at: In Workshop of Mitigation of the Earthquake Effects in Towns and in Industrial Regional Districts. Italy.

Li T.B., 2012. Damage to mountain tunnels related to the Wenchuan earthquake and some suggestions for aseismic tunnel construction. B. Eng. Geol Environ. 71(2), 297-308.

Lin A., Satsukawa T., Wang M., et al. 2016. Coseismic rupturing stopped by Aso volcano during the 2016 Mw 7.1 Kumamoto earthquake, Japan. Science, 354(6314): 869-874.

Li Y.S., 2006. Study on earthquake responses and vibration-absorption measures for mountain tunnel. Dissertation, Tongji University. (in Chinese)

Konagai K., Takatsu S., Kanai T., Fujita T., Ikeda T., Johansson J., 2009. Kizawa tunnel cracked on 23 October 2004 Mid-Niigata earthquake: an example of earthquake-induced damage to tunnels in active-folding zones. Soil Dyn. Earthquake Eng. 29(2), 394-403.

Power M.S., Rosidi D., Kaneshiro, J.Y., 1998. Seismic vulnerability of tunnels and underground structures revisited. In: Ozedimir L(ed) Proceedings of the North American Tunneling’98, Balkema, Rotterdam, pp 243-250.

Saito T., Mukouyama M., Taguchi Y., 2007. Damages to railroad tunnels in the Niigataken Chuetsu-oki Earthquake Shinetsu line Yoneyama to kashiwazaki. Tunn. Undergr. 38(12),891-900. (In Japanese)

Sharma S., Judd W. R., 1991. Underground opening damage from earthquakes. Eng. Geol. 30(3-4), 263-276.

Shen Y.S., Gao B., Yang X.M., et al., 2014. Seismic damage mechanism and dynamic deformation characteristic analysis of mountain tunnel after Wenchuan earthquake. Eng. Geol. 180, 85-98.

Shimizu M., Kurisu M., Katou S., 2005. Damages of railway tunnels by Niigata Chuetsu earthquake. Tunn. Undergr. 36(5),421-428. (In Japanese)

Shimizu M., Saito T., Suzuki S., Asakura T., 2007. Results of survey regarding damages of 
railroad tunnels caused by the Mid Niigata Prefecture Earthquake in 2004. Tunn Undergr 38(4),265-273. (In Japanese)

Towhata I., 2008. Geotechnical earthquake engineering. Springer Science \& Business Media.

Wang W.L., Wang T.T., Su J.J., et al., 2001. Assessment of damage in mountain tunnels due to the Taiwan Chi-Chi Earthquake. Tunn. Undergr. Sp. Tech. 16(3), 133-150.

Wang Z.Z., Gao B., Jiang Y.J., et al. , 2009. Investigation and assessment on mountain tunnels and geotechnical damage after the Wenchuan earthquake. Sci. China. Ser. E. 52(2), 546-558.

Yashiro K., Kojima Y., Shimizu M., 2007. Historical earthquake damage to tunnels in Japan and case studies of railway tunnels in the 2004 Niigataken-Chuetsu earthquake. Q. R. of RTRI 48(3), 136-141.

Yu H.T., Chen J.T., Bobet A., et al., 2016a. Damage observation and assessment of the Longxi tunnel during the Wenchuan earthquake. Tunn. Undergr. Sp. Tech. 54, 102-116.

Yu H.T., Chen J.T., Yuan Y, et al., 2016b. Seismic damage of mountain tunnels during the 5.12 Wenchuan earthquake. J. Mt. Sci. 13(11): 1958-1972.

Yu H.T., Yuan Y., Liu X., et al., 2013. Damages of the Shaohuoping road tunnel near the epicentre. Struct. Infrastruct. E. 9(9): 935-951.

Yu Y.Y., Guo X., Gao B., et al., 2013. Research on seismic damage mechanism of the secondary lining's ring cracks in mountain tunnel. J. Shenyang Jianzhu U: Nat. Sci. 29(1), 86-92.(in chinese) 


\section{Table Captions}

Table 1 Measured maximum ground acceleration at different observation sites induced by the mainshock of Kumamoto earthquake

\section{Figure Captions}

Figure 1 Location of the Tawarayama Tunnel and epicenter of the Kumamoto Earthquakes Figure 2 Typical cross section of the Tawarayama Tunnel

Figure 3 Geological profile of the Tawarayama Tunnel

Figure 4 Peak acceleration distribution of the Kumamoto Earthquakes in Japan.(a) peak acceleration contour map of foreshock on April 14, 2016;(b) peak acceleration contour map of mainshock on April 16, 2016 (data from K-NET, the National Research Institute for Earth Science and Disaster Prevention of Japan)

Figure 5 Acceleration waves measured at the Nakamatsu observation site during the Mj7.3 Kumamoto Earthquake on April 16, 2016.(a) acceleration waves of the NS, EW and UD component; (b) acceleration wave of the NS, EW and UD component from time of 15 s to 30s (data from GSI, the Geospatial Information Authority of Japan).

Figure 6 Distribution of seismic damages to the Tawarayama Tunnel by the 2016 Kumamoto Earthquake

Figure 7 Number and proportion of seismic damages to the Tawarayama Tunnel by the 2016 Kumamoto Earthquake

Figure 8 Sketch of the severe seismic damages to the Tawarayama Tunnel by the 2016 Kumamoto Earthquake

Figure 9 Ring crack of concrete lining. (a) ring crack in the spans from S119 to S126 in the Tawarayama Tunnel; (b) sketch and mapping result of ring crack

Figure 10 Longitudinal crack of concrete lining. (a) longitudinal crack in the Tawarayama 
Tunnel; (b) sketch and mapping result of longitudinal crack

Figure 11 Transverse and inclined crack of concrete lining. (a) transverse and inclined crack in the Tawarayama Tunnel; (b) sketch and mapping result of transverse and inclined crack Figure 12 Axial deformation mode and mechanism of mountain tunnels under seismic wave Figure 13 Spalling and collapse of concrete lining in the Tawarayama Tunnel. (a) concrete lining spalling along with inclined crack; (b) large area vault collapse of crown at spans of S166 and S167;(c) concrete lining fallings

Figure 14 Cross section deformation mechanism of mountain tunnels under seismic wave Figure 15 Different types of pavement damage in the Tawarayama Tunnel.(a) transverse cracking of pavement;(b) maintaining roadway uplift at the left side of maintaining roadway.

Figure 16 Groundwater leakage in the Tawarayama Tunnel.(a) leakage in construction joint; (b) leakage in lining concrete with lining crack

Figure 17 Sketch of ring cracks in spans from S119 to S126 and corresponding estimated spacing. ( $i$ denotes the No. of ring crack )

Figure 18 Estimated spacing of continuous ring cracks in the Tawarayama Tunnel 
Figure 1




Figure 2

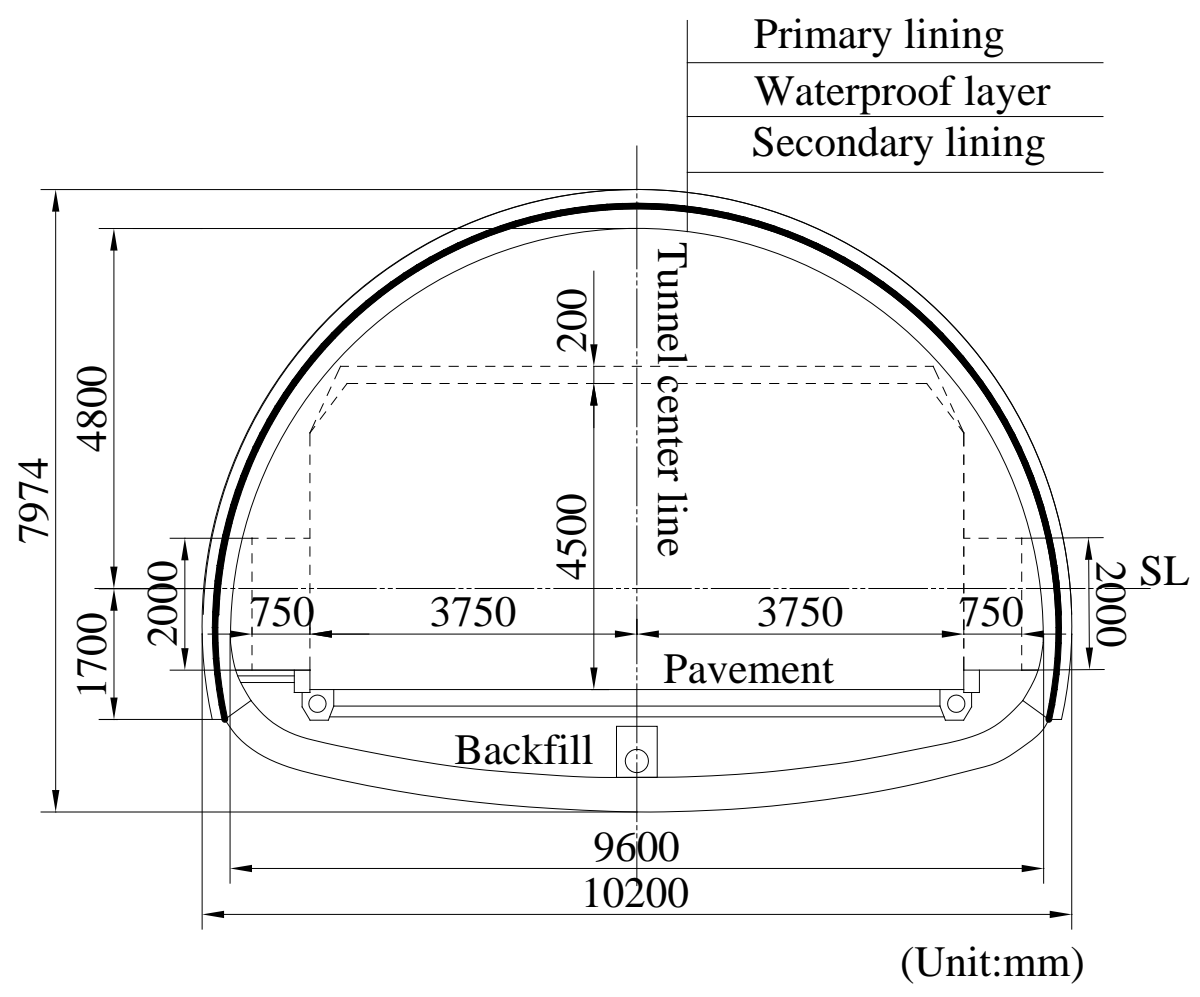


Figure 3

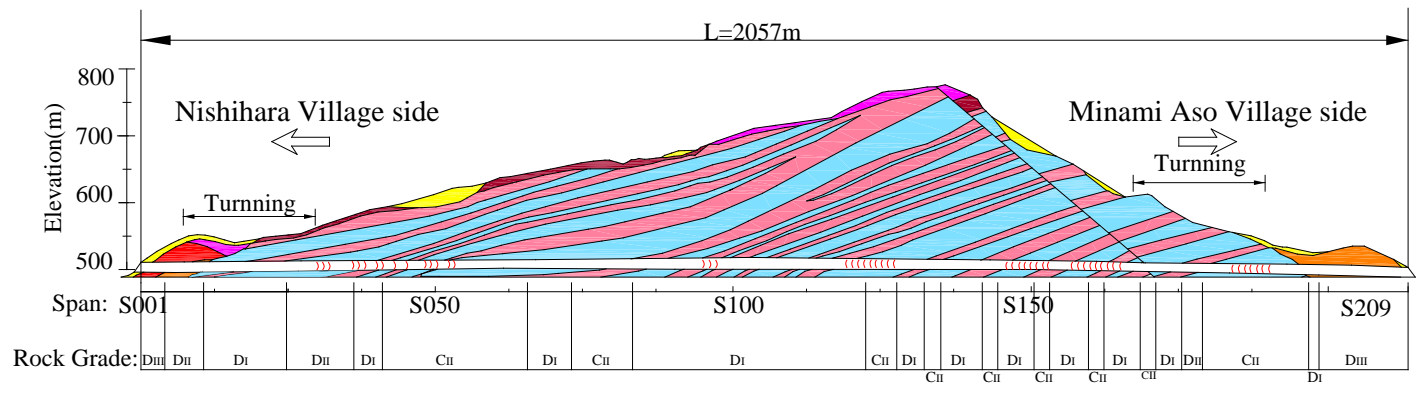

Aso-2 Pyroclastic Flow Deposit $\square$ Old Talus Deposit $2 \square$ Young Talus Deposit $S: H=1: 200 \quad V=1: 100$

$\square$ Aso-4 Pyroclastic Flow Deposit $\square$ Old Talus Deposit $3 \square$ Andesite $1 \square$ Andesite $2 \curvearrowright$ ring crack 
Figure 4

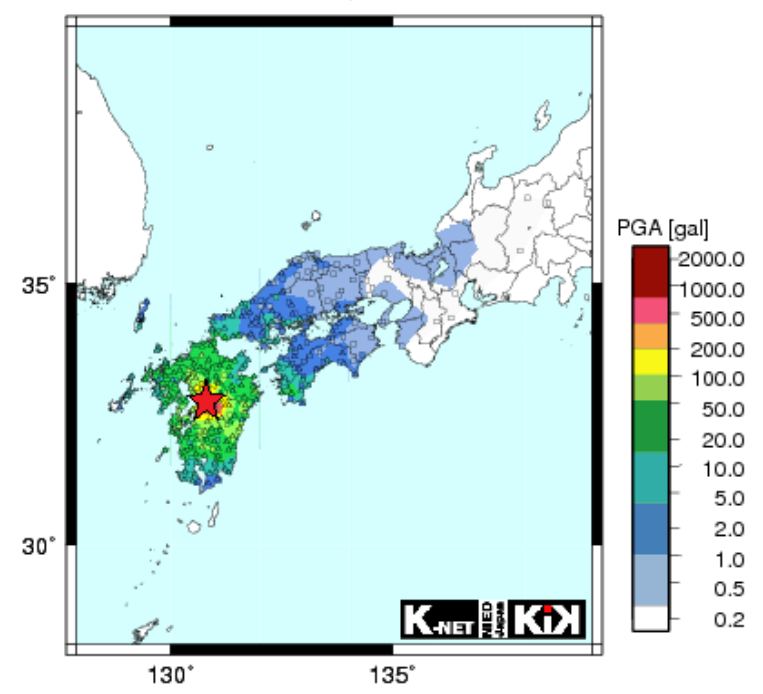

$\triangle$ K-NET $\square$ KiK-net $\star$ Epicenter(JMA)

2016/04/14-21:26 32.742N 130.808E 11km M6.5

(a)

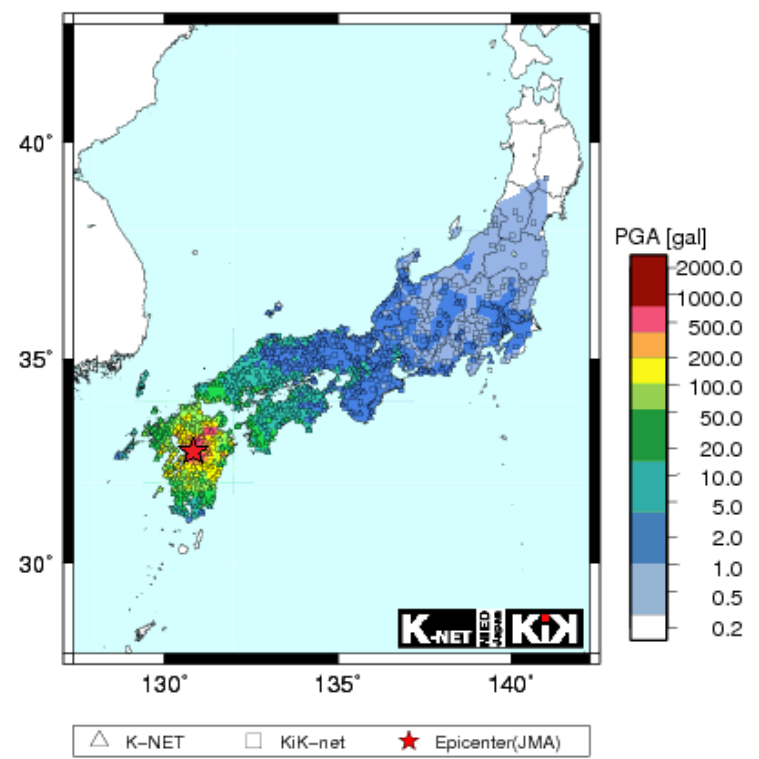

2016/04/16-01:25 32.753N 130.762E 12km M7.3

(b) 
Figure 5

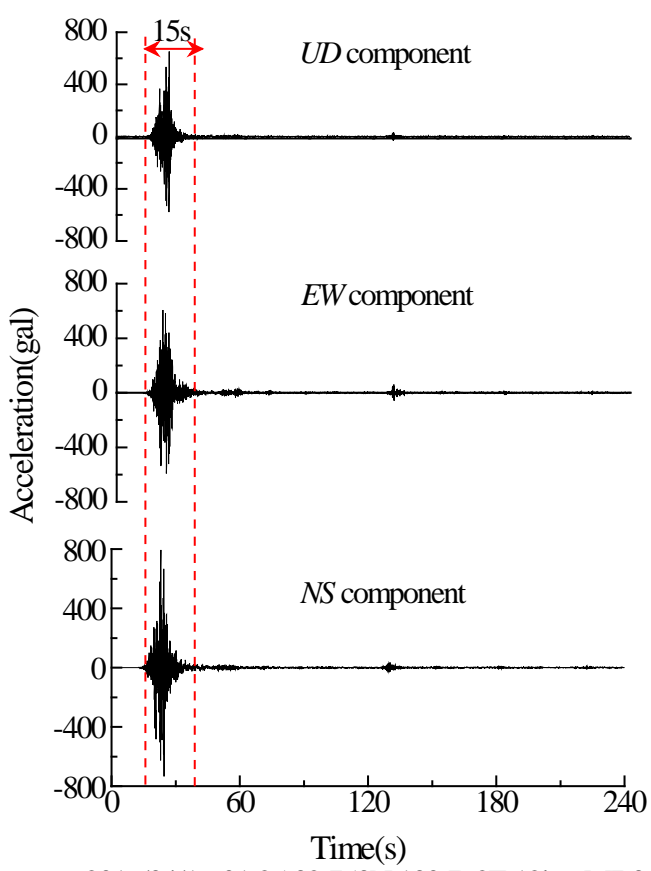

2016/04/16-01:25 32.753N 130.762E 12km M7.3

(a)

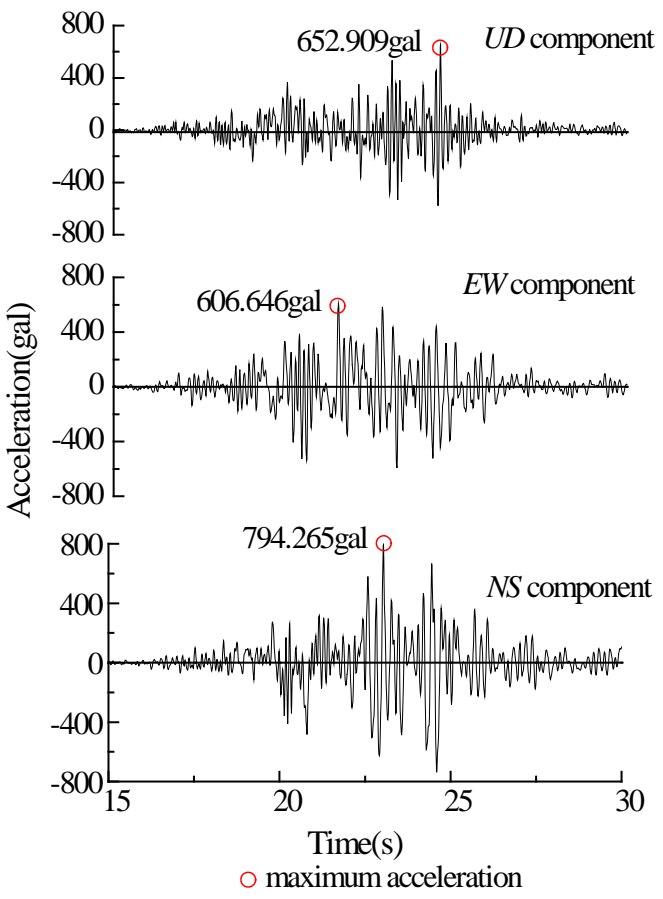

(b) 
Figure 6

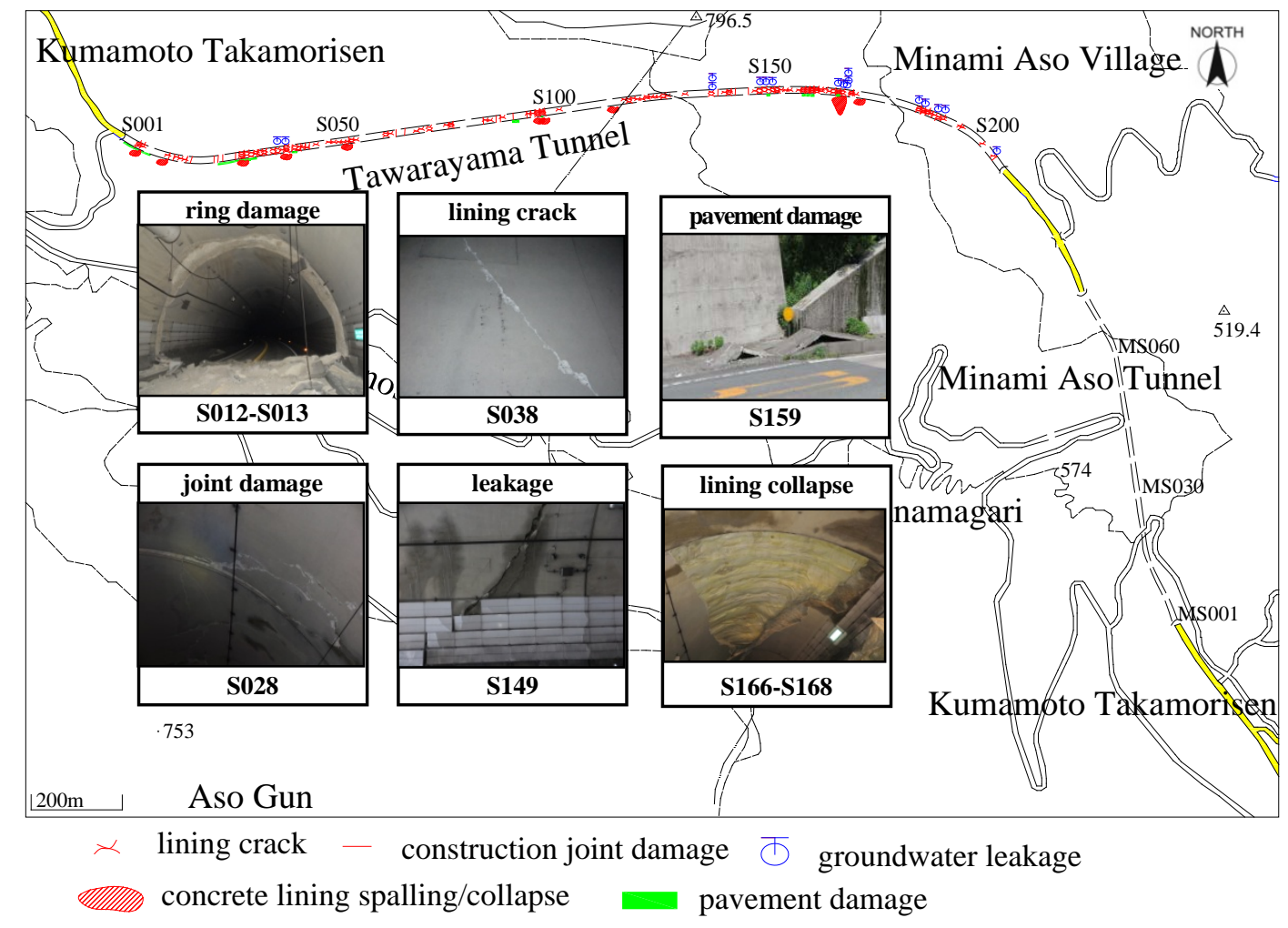


Figure 7

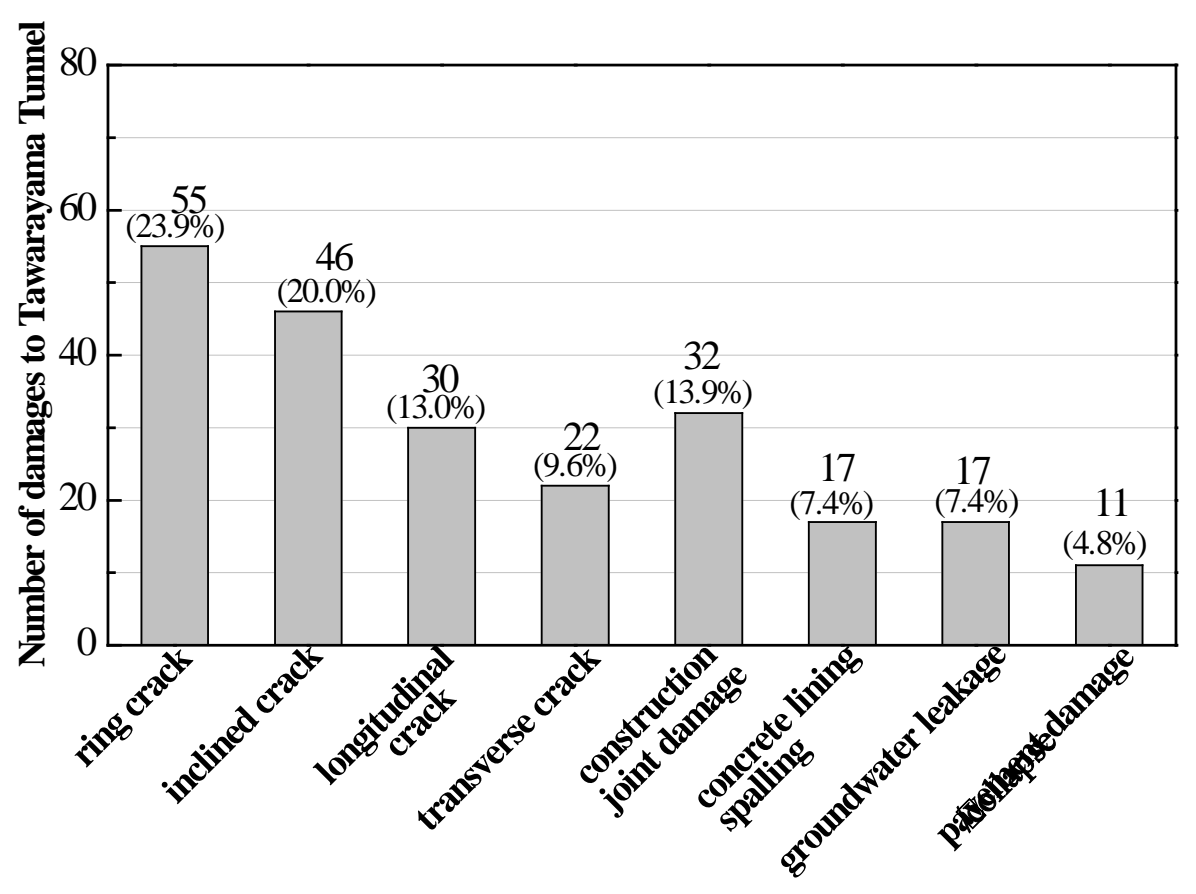


Figure 8
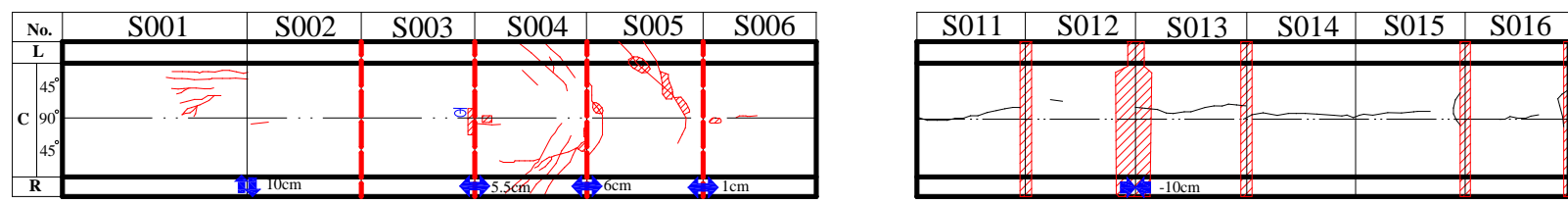

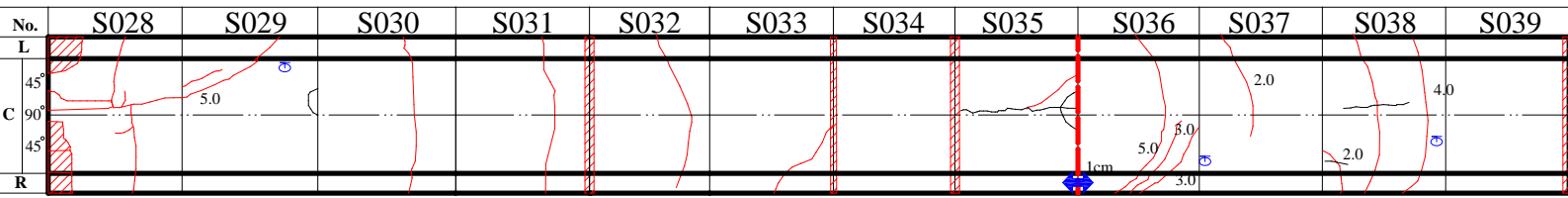
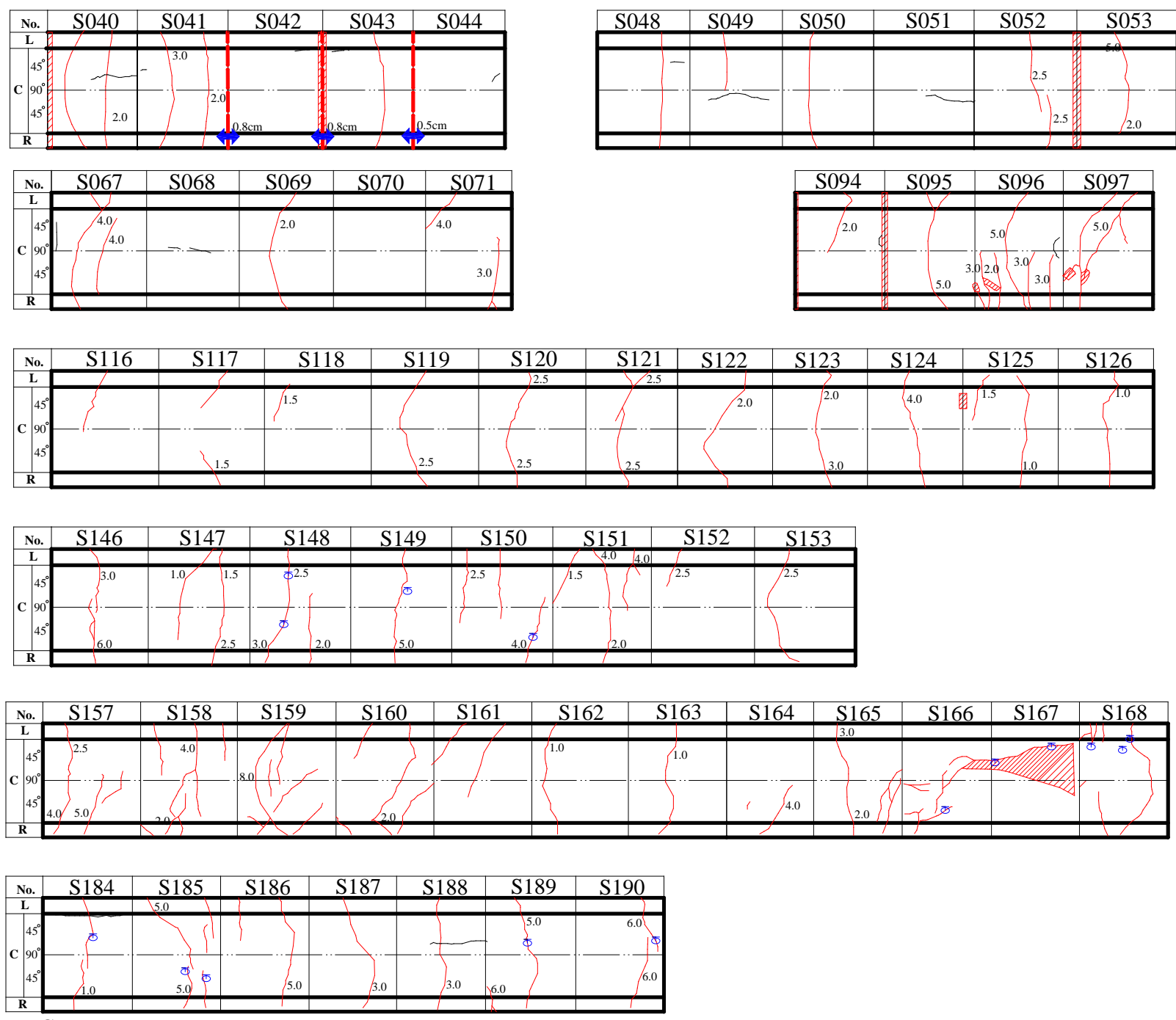

C: crown L: left side wall $\mathrm{R}$ : right side wall

10 lining crack; 10: lining crack opening(unit:mm) W concrete lining spalling/collapse Ð groundwater leakage

- construction joint damage construction joint opening/compression 
Figure 9

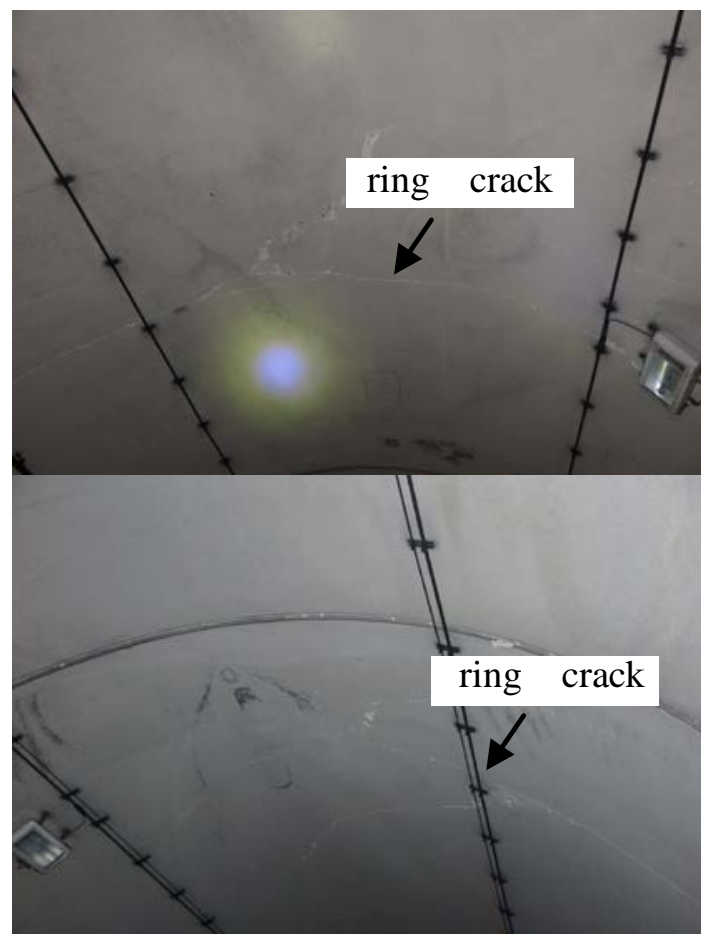

(a)

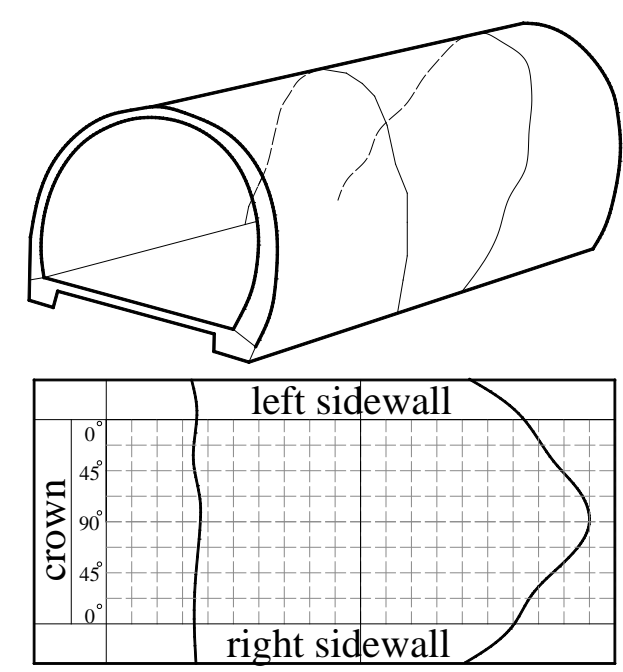

(b) 
Figure 10

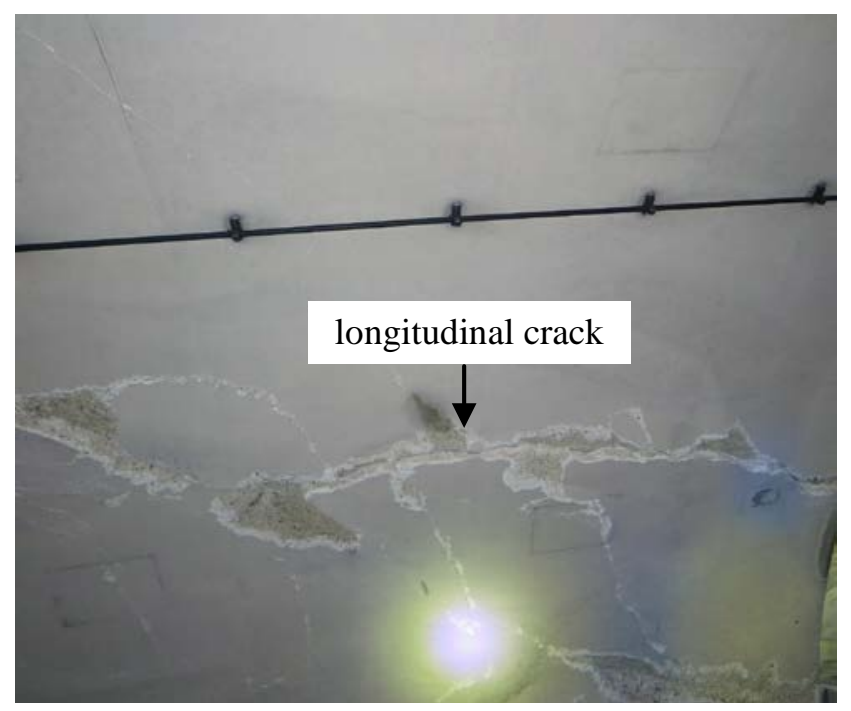

(a)
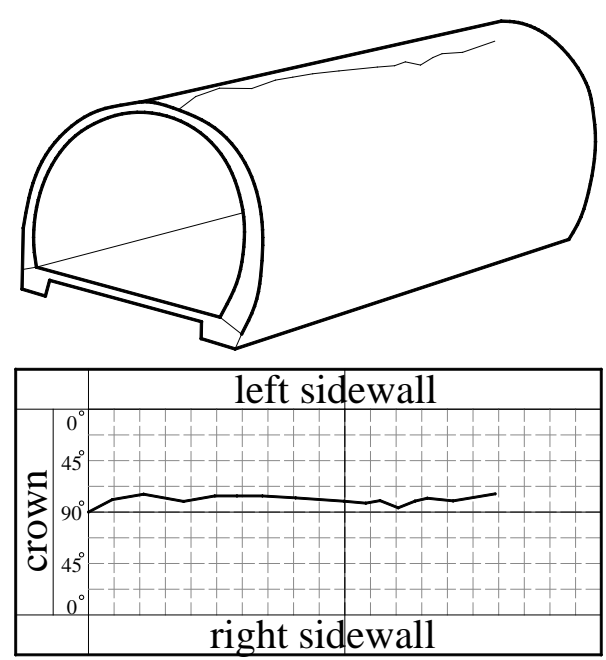

(b) 
Figure 11

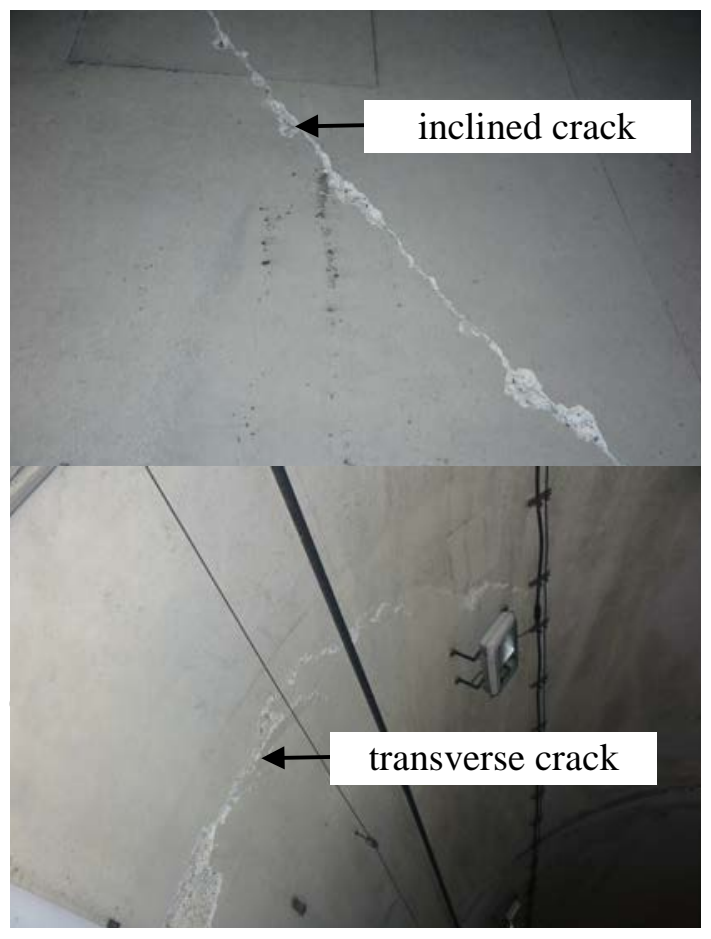

(a)
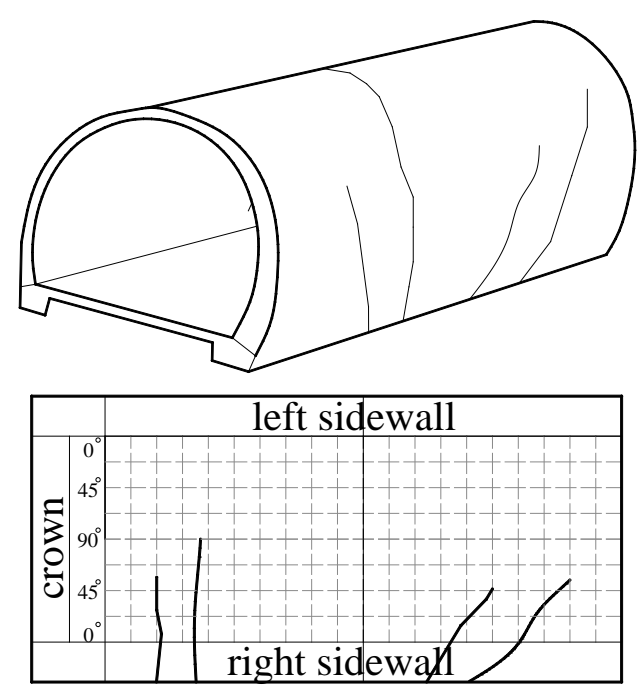

(b) 
Figure 12

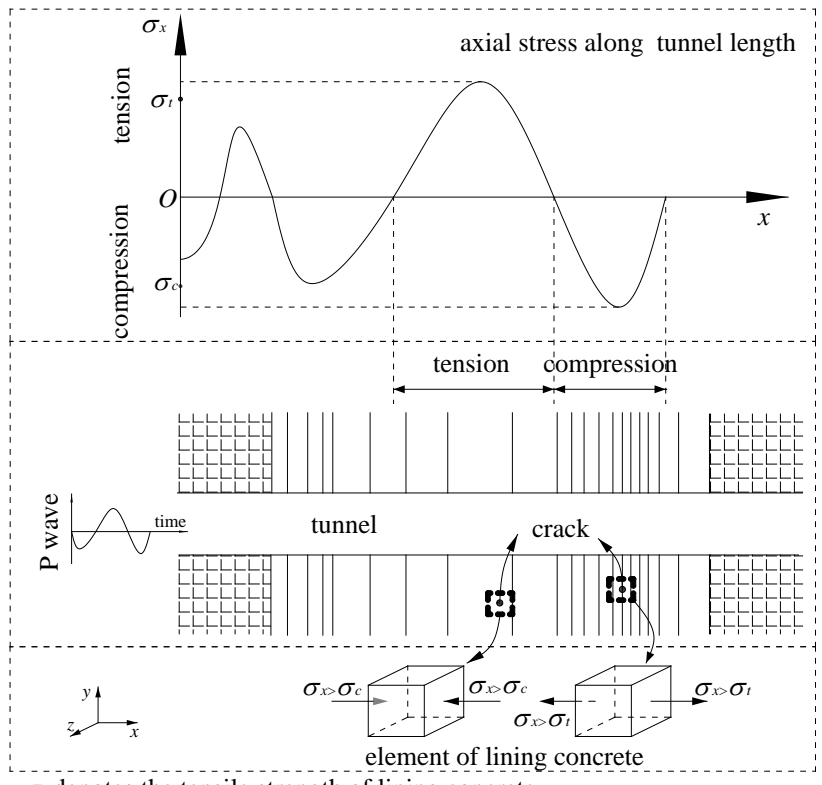

$\sigma_{\mathrm{t}}$ denotes the tensile strength of lining concrete

$\sigma_{\mathrm{c}}$ denotes the compression strength of lining concrete 
Figure 13

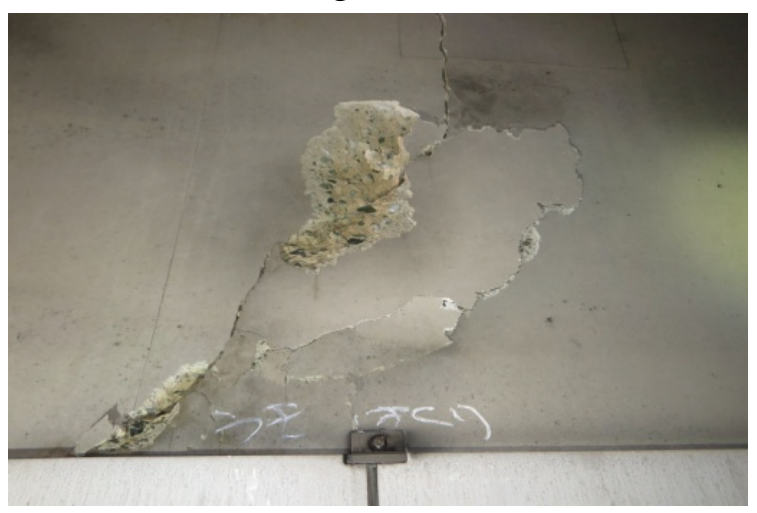

(a)

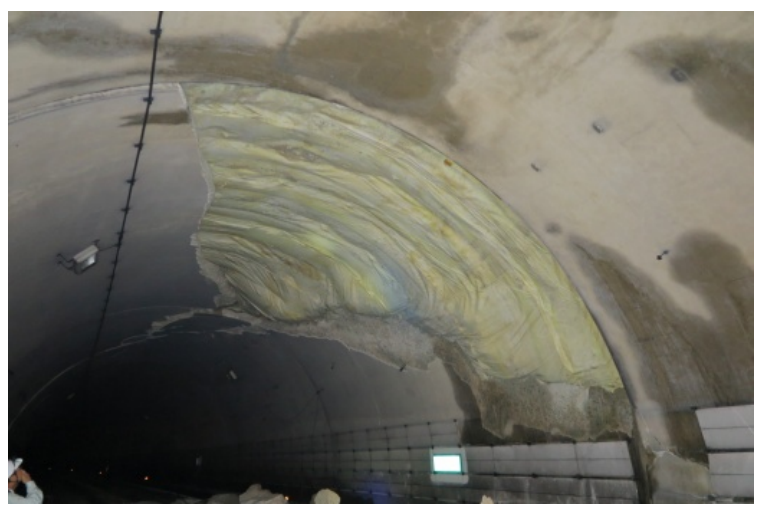

(b)

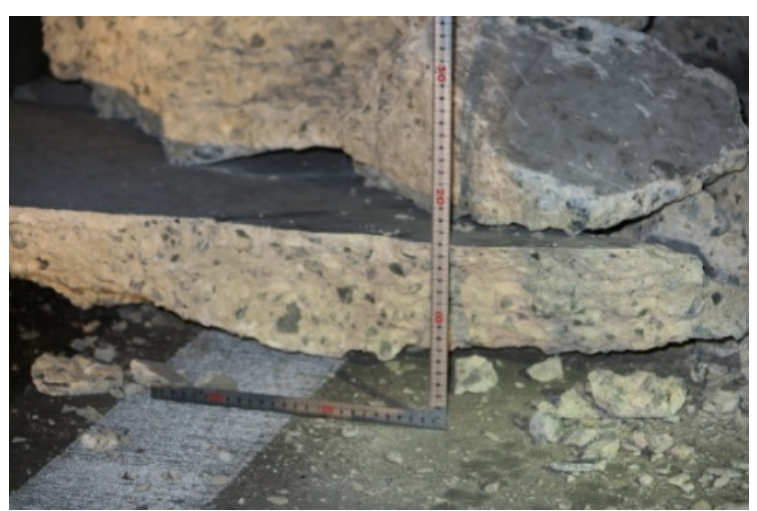

(c) 


\section{Figure 14}

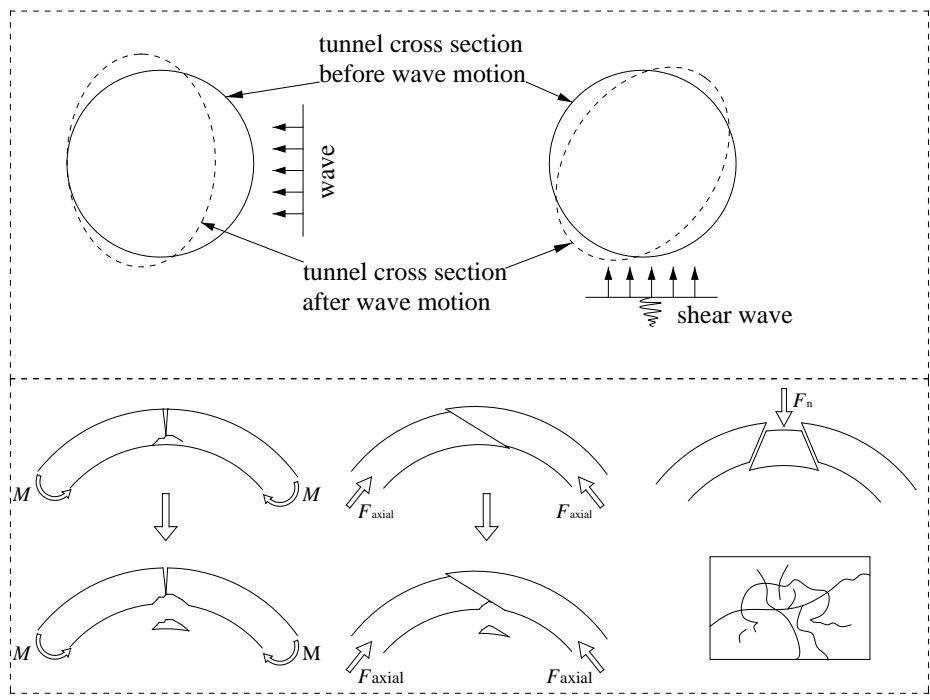


Figure 15

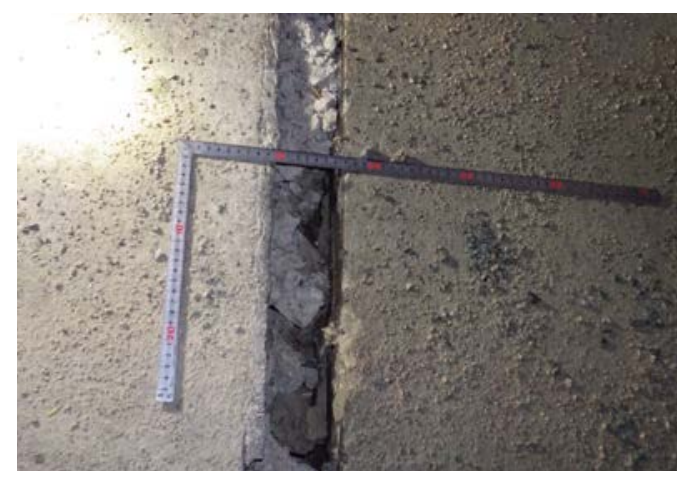

(a)

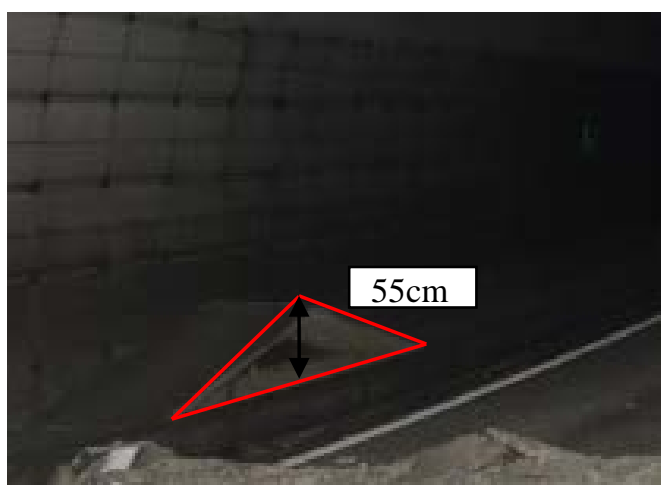

(b) 
Figure 16

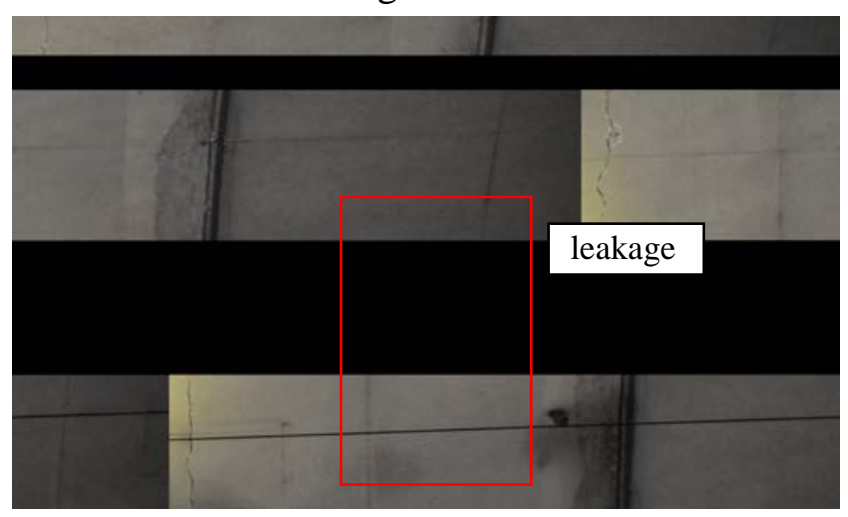

(a)

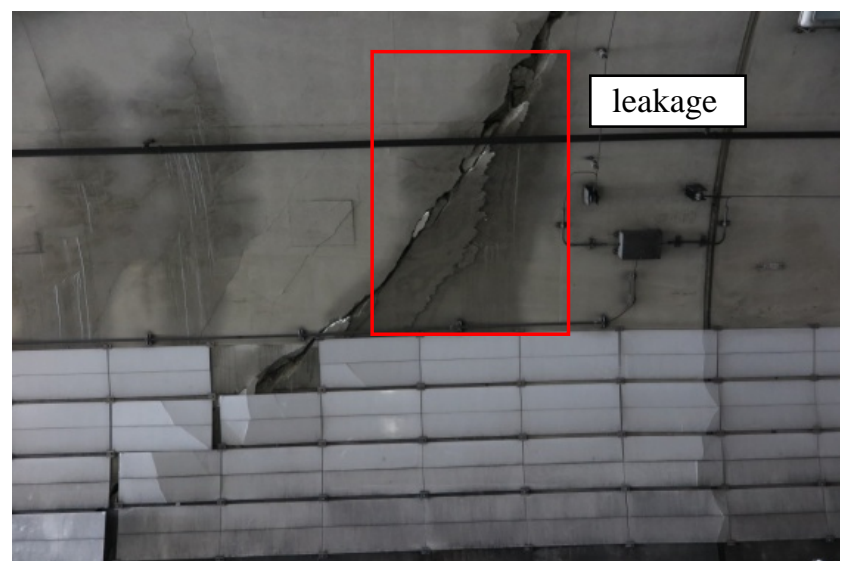

(b) 
Figure 17

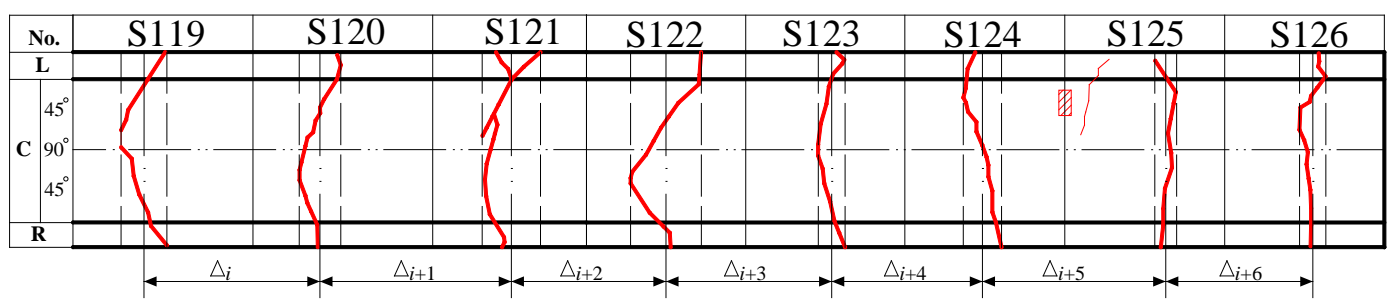


Figure 18

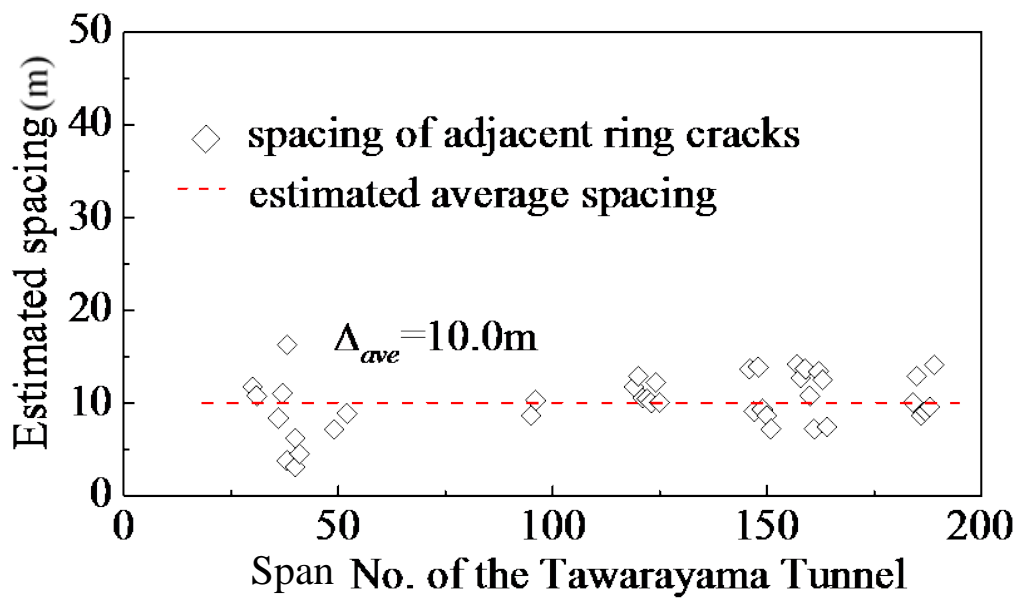


Table 1

\begin{tabular}{|c|c|c|c|c|c|c|}
\hline \multirow[t]{2}{*}{ Site code } & \multirow[t]{2}{*}{ Site location } & \multirow[t]{2}{*}{ Intensity } & \multicolumn{3}{|c|}{$\begin{array}{l}\text { Maximum ground acceleration } \\
\left(\mathrm{gal}=\mathrm{cm} / \mathrm{s}^{2}\right)\end{array}$} & \multirow{2}{*}{$\begin{array}{c}\text { Epicenter distance } \\
(\mathrm{km})\end{array}$} \\
\hline & & & NS & EW & UD & \\
\hline 9CF & Matsubase-machi, Uki-shi & 6 & 492.8 & 342.6 & 313.9 & 14.2 \\
\hline EEB & Kasuga, Nishi-ku & 6 & 606.0 & 551.6 & 405.3 & 7.5 \\
\hline EED & Nakamatsu, Minami Aso Village & 6 & 794.5 & 606.8 & 653.1 & 32.3 \\
\hline 9D2 & Ōyano-machi, Kami-amakusa-shi & 6 & 262.1 & 334.4 & 122.3 & 36.3 \\
\hline $5 \mathrm{E} 5$ & Hirayamashin-machi,Yatsushiro-shi & 5 & 171.8 & 175.6 & 82.5 & 34.6 \\
\hline 9D0 & Ashikita, Ashikita-machi & 5 & 138.6 & 124.9 & 41.4 & 56.9 \\
\hline EF0 & $\begin{array}{l}\text { Nishiaida Shimo-machi, } \\
\text { Hitoyoshi-shi }\end{array}$ & 5 & 111.7 & 102.0 & 50.4 & 61.2 \\
\hline
\end{tabular}

